\title{
Autism spectrum disorder: early identification and management in primary care
}

\author{
Li Ping Marianne Tsang ${ }^{1}$, MBBS, Choon How $\underline{H o w}^{2,3}$, MMed, FCFP, Sita Padmini Yeleswarapu ${ }^{4}$, MBBS, FRCPCH,
} Chui Mae Wong ${ }^{4}$, FRCPCH, PhD

Nicky, a 12-month-old boy, came with his mother to your clinic. He had a four-day history of cough and sore throat. His mother mentioned in passing that Nicky had always been a quiet child who made poor eye contact with her. Nicky was very quiet throughout the consultation and neither smiled nor waved at you or his parents. He did not seem to respond to you calling his name. Other than a mildly injected pharynx, he had no abnormalities on physical examination and no dysmorphic features.

\section{WHAT IS AUTISM SPECTRUM DISORDER?}

'Autism', derived from the Greek word 'autos', or 'self', refers to someone who 'lives in a world of his own'. Hence, autism spectrum disorder (ASD) is a neurodevelopmental condition that affects a person's ability to make sense of the world and relate to other people. It is characterised by persistent deficits in social communication and interaction, as well as restricted, repetitive patterns of behaviour and interests. These manifest during the early developmental period and cause clinically significant impairment of social and occupational function (Box 1).(1) The Diagnostic and Statistical Manual of Mental Disorders (DSM), Fifth Edition, refers to ASD as a single condition with different levels of severity, collectively representing four subtypes that were previously defined in DSM-IV (autistic disorder, Asperger's syndrome, childhood disintegrative disorder and pervasive developmental disorder not otherwise specified). ${ }^{(1)}$ ASD is also associated with psychiatric comorbidities such as anxiety, aggression, attention deficit hyperactivity disorder and obsessivecompulsive disorder. ${ }^{(2)}$

The exact aetiology of ASD is unknown; it is thought to have strong and complex genetic underpinnings with modulation of phenotypic expression by environmental factors. ${ }^{(3)}$ Normal childhood vaccines have been falsely implicated in the causation of ASD, and extensive research has now proven no link between vaccination and ASD. ${ }^{(4)}$ Factors associated with increased risk of ASD include: ${ }^{(5)}$ male gender; family history of sibling or parent with ASD; advanced paternal and maternal age; prematurity (gestational age $<35$ weeks) or antenatal infections; antenatal exposure to medications (e.g. valproate and antidepressants); and genetic syndromes such as fragile $X$ syndrome, tuberous sclerosis, Rett syndrome, Down syndrome, muscular dystrophy and neurofibromatosis.

ASD is not uncommon. Based on local data from KK Women's and Children's Hospital and National University Hospital, the prevalence of ASD in Singapore is estimated to be one in 100 individuals, and most children are formally diagnosed at approximately three years of age. ${ }^{(6)}$

\section{WHY IS EARLY DETECTION IMPORTANT?}

Early detection is important because early diagnosis and early intervention programmes have been shown to improve functional outcomes and quality of life. ${ }^{(7,8)}$ Unfortunately, early diagnosis of ASD can be challenging. It is often diagnosed after the age of three years, despite caregivers raising concerns for possible ASD at 15-22 months. ${ }^{(9,10)}$ The presentation of ASD can differ greatly from one child to the next. Some are perceived by parents as 'different' during the first few months of life, while others present with delayed language development during the second year of life, and still others develop normally until 12-24 months but regress thereafter ('autistic regression'). Locally, early diagnosis of ASD can be challenging when parents have poor awareness of the early symptoms of ASD or when they may not be the main caregivers; for instance, when working parents rely on the support of grandparents or domestic helpers. In such cases, the physican can consider taking collaborative histories from these caregivers.

\section{The role of primary care in early detection}

Being at the frontline of community healthcare, family physicians are well placed to screen for ASD. Family physicians can opportunistically look for features of ASD when children attend clinics for acute issues, and systemically screen for ASD during scheduled well-child developmental assessments. The Modified Checklist for Autism in Toddlers, Revised with Follow-up, (i.e. M-CHAT R/F) ${ }^{(11)}$ is one such screening tool. It has been recommended by the American Academy of Pediatrics for use during scheduled well-child assessments at 18 and 24 or 30 months, and is validated for use in the Singapore population. ${ }^{(12)}$

${ }^{1}$ SingHealth Polyclinics - Punggol, ${ }^{2}$ Care and Health Integration, Changi General Hospital, ${ }^{3}$ Family Medicine Academic Clinical Programme, SingHealth Duke-NUS Academic Medical Centre, ${ }^{4}$ Department of Child Development, KK Women's and Children's Hospital, Singapore

Correspondence: Dr Li Ping Marianne Tsang, Resident, SingHealth Polyclinics - Punggol, 681 Punggol Drive, Singapore 820681. marianne.tsang@gmail.com 


\section{Box 1. Features of autism spectrum disorder:}

Persistent deficits in social communication and interaction in multiple contexts

- Deficits in social-emotional reciprocity, e.g. abnormal social approach; failure of normal back-and-forth conversation; and reduced sharing of interests, emotions and affect.

- Deficits in non-verbal communicative behaviours used for social interaction, e.g. abnormalities in eye contact and body language, deficits in understanding and use of facial expression or gestures, and poor integration of verbal and non-verbal communication.

- Deficits in developing, maintaining and understanding relationships, e.g. difficulties in sharing imaginative play or making friends, absence of interest in peers, and difficulties adjusting behaviour to suit various social contexts.

Restricted, repetitive patterns of behaviour, interests or activities

- Stereotyped or repetitive motor movements, use of objects or speech, e.g. simple motor stereotypies, lining up toys or flipping objects, echolalia, and idiosyncratic phrases.

- Insistence on sameness, inflexible adherence to routines, ritualised patterns or verbal/non-verbal behaviour, e.g. extreme distress at small changes, difficulties with transitions, rigid thinking patterns, greeting rituals, and need to take the same route or eat the same food every day.

- Highly restricted, fixated interests that are abnormal in intensity or focus, e.g. strong attachment to or preoccupation with unusual objects, and excessively circumscribed or perseverative interest.

- Hyper- or hyporeactivity to sensory input or unusual interests in sensory aspects of the environment, e.g. apparent indifference to pain or temperature, adverse response to specific sounds or textures, excessive smelling or touching of objects, and visual fascination with lights or movement.

\section{WHAT ARE THE EARLY SIGNS?}

As some children with ASD have good verbal ability, the condition is easily missed. Therefore, maintain a high index of suspicion for ASD in children with atypical language (e.g. echolalia, pronoun reversal, calling self by name or only talking about topics of their own interest), poor social interaction, and rigidity in thought or behaviour. The early warning signs of ASD are summarised in Box 2.

\section{WHAT SHOULD I DO IF I SUSPECT ASD?}

If ASD is suspected, the child should be referred to appropriate specialist centres for a comprehensive multidisciplinary assessment and diagnosis. In addition to public sector centres (Box 3$){ }^{(13)}$ services are also available in the private sector.

A number of other conditions (e.g. intellectual disability, social communication disorder and developmental language disorder) mimic ASD, in that they also impair social communication, social interaction and/or may be associated with stereotypic behaviours. It is important for the specialist centres to distinguish between ASD and these conditions, as the more subtle differences may be beyond the scope of the family physician.

\section{Box 2. Early warning signs for autism spectrum disorder:}

At 12 months

- No cooing or reciprocal babbling

- No use of social gestures (e.g. waving, pointing to indicate interest in objects or people)

\section{At 18 months}

- No shared enjoyment (e.g. bringing toys of interest to show caregivers)

- No meaningful single words

At 24 months

- No spontaneous (non-echoed) two-word phrases

- No interest in other children

At any age

- Poor eye contact

- No response when name is called

- Developmental regression; loss of existing language, words or social skills

\section{Box 3. Referral centres for suspected ASD:(13)}

\section{Preschool-aged children}

- Department of Child Development, KK Women's and Children's Hospital

- Child Development Unit, National University Hospital (NUH)

School-aged children (Primary 1 and above)

- Child Guidance Clinic, Institute of Mental Health

- Department of Psychological Medicine, NUH

- Department of Psychological Medicine, Khoo Teck Puat Hospital

- Department of Psychological Medicine, Changi General Hospital (patients aged $\geq 13 \mathrm{yr}$ )

- REACH (Response, Early Intervention and Assessment in Community Mental Health) for patients with mild symptoms

\section{WHAT EARLY INTERVENTIONS ARE AVAILABLE FOR CHILDREN?}

Many children with ASD benefit from early intervention, including intensive structured teaching and practice in social interaction, communication, thinking, self-help and independence. Many interventions that have evidence of benefit are available, including occupational therapy, speech-language therapy, Picture Exchange Communication System, the TEACCH $®$ (Treatment and Education of Autistic and Related Communication Handicapped Children) programme and applied behavioural analysis. In Singapore, these interventions are largely administered within small-group settings in EIPIC (Early Intervention Programme for Infants and Children) centres. There are many EIPIC centres across Singapore, run by both government-funded voluntary welfare organisations (VWOs) and private operators. Children with ASD can also receive these interventions via individual therapy if needed. Providers of individual therapy include those in the private sector and VWOs such as the Thye Hua Kwan Children's Therapy Centre and SPD's Continuing Therapy Programme.

Some children with ASD have mild developmental needs. For these children, shorter-term, school-based intervention programmes such as the Development Support and Learning Support programme prepare them for mainstream primary school education. We recommend visiting the SG Enable website on 
'Services for Children with Special Needs' for the most current information. ${ }^{(14)}$ The Autism Resource Centre (Singapore) website is also a useful resource for parents. ${ }^{(15)}$

\section{HOW CAN INDIVIDUALS WITH ASD BE SUPPORTED?}

Support for children with ASD continues in their schooling years and beyond. Some students will be able to learn with their peers in mainstream schools, with support from allied educators. Others require more specialised learning environments in special education schools (e.g. Pathlight School, Eden School, St Andrew's Autism Centre, Rainbow Centre and AWWA [Asian Women's Welfare Association] School), which allow them to learn in a more individualised manner with time and opportunity to apply the skills they learn.

As a child with ASD enters adolescence and adulthood, there is a continued need for support and guidance - for instance in negotiating higher education options, meeting work productivity demands, achieving vocational skills through job coaching, understanding and complying to social rules and expectations, developing positive relationships with others, understanding and coping with sexuality issues, and managing stress.

With training, placement and support, people with ASD can find employment in an area that matches their abilities and interests. Locally, the Employability and Employment Centre offers job training, placement and support for adults with ASD. More information is available at its website. ${ }^{(16)}$

\section{Support from the family physician for individuals on follow-up}

Children with ASD may consult family physicians for common ailments such as cough or diarrhoea. As they may have difficulty expressing themselves and in communicating their symptoms to caregivers and physicians, physicians should be alert for varied presentations of illness.

Beyond managing acute conditions, family physicians have a role in the continued support of children who are on follow-up with specialist services for ASD. Firstly, they should check that the child remains on active follow-up and continues to receive interventions, and reinforce the importance of doing so. Secondly, they should ensure that the child receives all vaccinations as per the national childhood immunisation schedule. Some parents may require reassurance that there is no link between vaccination and ASD. Thirdly, the family physician can also explore how the child's family is coping. Family is the cornerstone to the care of these children: it is they who partner with therapists to incorporate interventions taught during therapy into the child's daily routine. The family physician cares for the entire family. Look for stressors such as parenting, marital, financial and parental mental health issues, with a view to referring family members to appropriate counselling and support services (e.g. family service centres) if needed. Finally, adolescents and adults with ASD may have comorbid mental health conditions such as anxiety, depression, attention deficit hyperactivity disorder and obsessive-compulsive disorder that may need to be identified and addressed.

\section{IS THERE A ROLE FOR COMPLEMENTARY AND ALTERNATIVE MEDICINE?}

Parents of children with ASD may express an interest in the use of complementary and alternative medicine, including biologicallybased (e.g. dietary supplements; traditional Chinese medicine; gluten-free, casein-free diet; acupuncture; chelation therapy; and transcranial magnetic therapy) and non-biologically-based (e.g. art therapy and sensory integration therapy) modalities. As evidence for the efficacy of complementary and alternative medicine in ASD is sparse, the physician should not make any evidence-based recommendations on their use. ${ }^{(17)}$ Instead, families can be encouraged to share all interventions that they are pursuing with their physicians. Some non-biologically-based modalities (e.g. art therapy and music therapy) resemble normal childhood experiences and probably do no harm. Biologicallybased therapies, including supplements, may result in harm and should be monitored for side effects and potential drug interactions.

\section{TAKE HOME MESSAGES}

1. Family physicians have a role in the early detection of ASD. Apart from conducting well-child developmental assessments, they should screen for ASD opportunistically when children attend clinics for acute issues and pay attention to any concerns raised by caregivers.

2. When screening for ASD in very young children, look for delayed non-verbal developmental milestones (e.g. no waving, pointing, eye contact or spontaneous sharing by 12-18 months) and impaired social interaction (e.g. lack of interest in other children).

3. If ASD is suspected, refer the child to appropriate specialist centres as soon as possible.

4. Early interventions are available for children with ASD and have been shown to improve functional outcomes. Individuals with ASD can become productive, functional members of society with ongoing support.

Through further history-taking, you established that Nicky's parents had never observed him pointing to indicate his needs. Nicky was said to exhibit hand flapping when excited and did not tell others about his interests. You suspected early features of autism spectrum disorder and referred Nicky to the Department of Child Development at KK Women's and Children's Hospital for further assessment. He was enrolled in the Early Intervention Programme for Infants and Children and subsequently diagnosed with autism spectrum disorder. Four years later, you saw Nicky again for cough and fever. He had made significant progress in language development and social behaviour. He was preparing to enrol in preschool and was expected to join a mainstream primary school later on. 
ABSTRACT Autism spectrum disorder (ASD) is characterised by persistent deficits in social communication and interaction as well as restricted, repetitive patterns of behaviour and interests. Early detection and early intervention programmes improve functional outcomes. Family physicians should screen for ASD opportunistically when children attend clinics for acute issues and during scheduled well-child assessments. Early warning signs of ASD include the lack of social gestures at 12 months, using no meaningful single words at 18 months, and having no interest in other children or no spontaneous two-word phrases at 24 months. Children with suspected ASD should be referred to appropriate specialist centres as early as possible for multidisciplinary assessment and diagnosis.

Keywords: autism spectrum disorder, developmental screening, primary care well-child assessment

\section{REFERENCES}

1. American Psychiatric Association. The Diagnostic and Statistical Manual for Mental Disorders Fifth Edition (DSM-5). Washington DC: American Psychiatric Association Publishing, 2013.

2. Mannion A, Leader G. Comorbidity in autism spectrum disorder: a literature review. Res Autism Spectr Disord 2013; 7:1595-616.

3. Bailey A, Phillips W, Rutter M. Autism: towards an integration of clinical, genetic, neuropsychological, and neurobiological perspectives. J Child Psychol Psychiatry 1996; 37:89-126.

4. Spencer JP, Trondsen Pawlowski RH, Thomas S. Vaccine adverse events: separating myth from reality. Am Fam Physician 2017; 95:786-94.

5. Kolevzon A, Gross R, Reichenberg A. Prenatal and perinatal risk factors for autism: a review and integration of findings. Arch Pediatr Adolesc Med 2007; 161:326-33.

6. Wong $\mathrm{CM}, \mathrm{Koh} \mathrm{HC}$. Brief report: investigating the implications of applying the new DSM-5 Criteria for Diagnosing Autism Spectrum Disorder in a preschool population in Singapore. J Autism Dev Disord 2016; 46:3177-82.

7. Zwaigenbaum L, Bauman ML, Choueiri R, et al. Early intervention for children with autism spectrum disorder under 3 years of age: recommendations for practice and research. Pediatrics 2015; 136 Suppl 1:S60-81.

8. Warren Z, McPheeters ML, Sathe N, et al. A systematic review of early intensive intervention for autism spectrum disorders. Pediatrics 2011; 127:e1303-11.

9. Johnson CP, Myers SM; American Academy of Pediatrics Council on Children With Disabilities. Identification and evaluation of children with autism spectrum disorders. Pediatrics 2007; 120:1183-215.

10. Zuckerman KE, Lindly OJ, Sinche BK. Parental concerns, provider response, and timeliness of autism spectrum disorder diagnosis. J Pediatr 2015; 166:1431-9.

11. Dosreis S, Weiner CL, Johnson L, Newschaffer CJ. Autism spectrum disorder screening and management practices among general pediatric providers. J Dev Behav Pediatr 2006; 27 (2 Suppl):S88-94.

12. Koh HC, Lim SH, Chan GJ, et al. The clinical utility of the modified checklist for autism in toddlers with high risk 18-48 month old children in Singapore. J Autism Dev Disord 2014; 44:405-16.

13. Ministry of Health Singapore. Referral Guidelines for Children with Developmental, Learning or Behavioural Issues. MOH Circular No. 04/2019, 2019

14. SG Enable. Services for Children with Special Needs (0-6 Years). Available at: https://www.sgenable.sg/pages/content.aspx?path=/for-children/. Accessed Jan 1, 2019.

15. Autism Resource Centre (Singapore). Autism Resource Centre Home Page. Available at: https://www.autism.org.sg/. Accessed Jan 1, 2019.

16. Autism Resource Centre (Singapore). Employability \& Employment Centre Available at: https://www.autism.org.sg/core-services/e2c\#tab_e2cProgramme. Accessed Jan 1, 2019.

17. Levy SE, Hyman SL. Complementary and alternative medicine treatments for children with autism spectrum disorders. Child Adolesc Psychiatr Clin N Am 2015; 24: 117-43. 


\section{SINGAPORE MEDICAL COUNCIL CATEGORY 3B CME PROGRAMME} (Code SMJ 201907A)

1. Symptoms of autism spectrum disorder (ASD) first begin to manifest at 6-7 years of age.

2. ASD is a single condition with different levels of severity.

3. On developmental assessment, children with ASD may exhibit delayed development in the speech-language and/or social-behavioural domains.

4. Children with ASD may exhibit repetitive behaviours, such as lining up toys, and may exhibit unusually intense interest in a narrow range of toys or objects.

5. Obsessive-compulsive disorder should not be diagnosed in a child with ASD, as ASD is an adequate explanation for the child's obsessive-compulsive behaviour.

6. Receiving the measles, mumps and rubella vaccine increases the risk of ASD.

7. ASD is uncommon, with a prevalence of less than one in 1,000 individuals in Singapore.

8. Early diagnosis of ASD improves functional outcomes and quality of life.

9. Some children with ASD may develop normally in the first two years of life, but subsequently lose the language or social skills that they have learnt.

10. The Modified Checklist for Autism in Toddlers, Revised with Follow-up, is a useful screening tool for ASD.

11. A one-year-old child who is unable to say two-word phrases should be referred for assessment of suspected ASD.

12. A two-year-old child who does not point to objects of interest or play with other children should be referred for assessment of suspected ASD.

13. A child who is able to speak well is not likely to have ASD.

14. Differentials of ASD include intellectual disability and developmental language disorder.

15. Children with ASD may receive therapy at EIPIC (Early Intervention Programme for Infants and Children) centres or through school-based intervention programmes.

16. All children with ASD are ineligible to attend mainstream primary schools.

17. Job training, placement and support are available for adults with ASD.

18. Children with ASD may have difficulty communicating symptoms of acute illnesses such as cough and vomiting to their caregivers.

19. Children with ASD may default intervention programmes because of parental financial or mental health issues, and it is important to address these, such as by referring family members to counselling and support services.

20. Dietary supplements and modification have been shown to improve symptoms of ASD.

\begin{tabular}{|c|c|}
\hline True & False \\
\hline$\square$ & $\square$ \\
\hline$\square$ & \\
\hline$\square$ & $\square$ \\
\hline$\square$ & $\square$ \\
\hline$\square$ & $\square$ \\
\hline$\square$ & $\square$ \\
\hline$\square$ & $\square$ \\
\hline$\square$ & $\square$ \\
\hline$\square$ & $\square$ \\
\hline$\square$ & $\square$ \\
\hline$\square$ & $\square$ \\
\hline$\square$ & $\square$ \\
\hline$\square$ & $\square$ \\
\hline$\square$ & $\square$ \\
\hline$\square$ & $\square$ \\
\hline$\square$ & $\square$ \\
\hline$\square$ & $\square$ \\
\hline$\square$ & $\square$ \\
\hline$\square$ & $\square$ \\
\hline$\square$ & $\square$ \\
\hline
\end{tabular}

\section{Doctor's particulars:}

Name in full:

Specialty:
MCR no.:

Email:

\section{SUBMISSION INSTRUCTIONS:}

Visit the SMJ website: http://www.smj.org.sg/current-issue and select the appropriate quiz. You will be redirected to the SMA login page.

For SMA member: (1) Log in with your username and password (if you do not know your password, please click on 'Forgot your password?'). (2) Select your answers for each quiz and click 'Submit'.

For non-SMA member: (1) Create an SMJ CME account, or log in with your SMJ CME username and password (for returning users). (2) Make payment of SGD 21.40 (inclusive of $7 \%$ GST) via PayPal to access this month's quizzes. (3) Select your answers for each quiz and click 'Submit'.

RESULTS:

(1) Answers will be published online in the SMJ September 2019 issue. (2) The MCR numbers of successful candidates will be posted online at the SMJ website by 10 September 2019. (3) Passing mark is $60 \%$. No mark will be deducted for incorrect answers. (4) The SMJ editorial office will submit the list of successful candidates to the Singapore Medical Council. (5) One CME point is awarded for successful candidates. (6) SMC credits CME points according to the month of publication of the CME article (i.e. points awarded for a quiz published in the December 2017 issue will be credited for the month of December 2017, even if the deadline is in January 2018).

Deadline for submission (July 2019 SMJ 3B CME programme): 12 noon, 3 September 2019. 